\title{
A case of acquired tufted angioma in adulthood ${ }^{*}$
}

\author{
Filippo Pesapane $e^{1,2}$ \\ Silvia A Iberti-Violetti ${ }^{1,2}$
}

\author{
Gianluca Nazzaro ${ }^{1,2}$ \\ Raffaele Gianotti ${ }^{1,2}$
}

DOI: http:/ / dx.doi.org/ 10.1590/ abd1806-4841.20153733

Abstract Tufted angioma is a rare vascular tumor whose name derives from its histopathological appearance,
characterized by tufts of capillaries within the dermis. Its etiology and pathogenesis are uncertain. Tufted an-
gioma typically occurs during infancy or early childhood and displays various clinical patterns. It may present
as a subtle stain-like area that later thickens as a large plaque, infiltrated or dusky blue-purple lesion, or as an
exophytic, firm, violaceous, cutaneous nodule. Medical treatment is not necessary for tufted angioma, given its
benign nature and slow progression. Only clinical follow-up is therefore recommended.

Keywords: Hemangioma; Skin neoplasms; Vascular malformations

\section{INTRODUCTION}

Tufted angioma (TA) is a rare vascular tumor commonly localized in the skin and subcutaneous tissues and characterized by slow angiomatous proliferation. Most cases are usually acquired in childhood, with a protracted course, but it can also manifest in adulthood, as the case reported in this article. TA presents clinically as a subtle stain-like area that later thickens, as a large, plaquelike, infiltrated, red or dusky blue-purple lesion, or as an exophytic, firm, violaceous, cutaneous nodule. TA is solitary, but multifocal cases have been reported. ${ }^{1}$

Histologically, both acquired and congenital TAs demonstrate vascular tufts of tightly packed capillaries, randomly dispersed throughout the dermis in a typical "cannonball distribution" with crescent spaces surrounding the vascular tufts and lymphatic-like spaces within the tumor stromal. ${ }^{2}$ TA may persist unchanged or regress completely within a few years. ${ }^{3}$ Outpatient medications may include topical steroids or oral NSAIDs for the treatment of painful episodes associated with tufted angioma. Systemic corticosteroids and non-selective beta-adrenergic antagonist like propranolol have been used with success in a limited number of patients with tufted angioma, al- though this indication is not formally approved by the US Food and Drug Administration.

We report a case of an adult-onset TA localized on the shoulder of a 47-year-old woman.

\section{CASE REPORT}

We report the case of a red, infiltrated, solitary plaque measuring $9 \mathrm{~cm}$ in the major axis, which had appeared two months before consultation on the shoulder of a 47-year-old femal e patient (Figure 1). On palpation, the lesion was tender, fixed on the superficial and deep tissues. No pain or itching was reported.

Histological examination showed a slightly acanthotic epidermis and large vascular lobules in the full-thickness dermis (Figures 2 and 3). Each lobule was composed of aggregates of endothelial cells concentrically whorled along a preexisting vascular plexus. Immunohistochemistry showed positivity for CD31 and CD34, and negativity for smooth muscleactin (Figures 4 and 5).

A diagnosis of "A cquired Tufted Angioma" was made. Due to the benignity of this lesion and the frequent spontaneous regression of TA, no treatment was suggested.

Received on 30.05.2014

Approved by theAdvisory Board and accepted for publication on 16.06.2014

* Study conducted at the Department of Medical-Surgical Pathophysiology and Transplants, University of Milan - Fondazione IRCCS Ca' Granda Ospedale Maggiore Policlinico, Milan, Italy.

Financial Support: None.

Conflict of Interest: N one.

“Fondazione IRCCS Ca' Granda, Ospedale Maggiore Policlinico" - Milan, Italy.

University of Milan - Milan, Italy.

(2015 by Anais Brasileiros de Dermatologia 


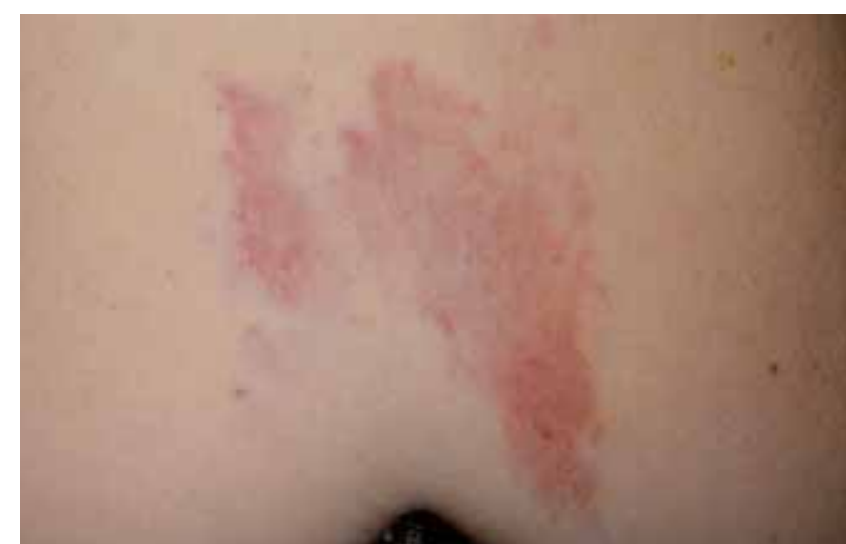

Figure 1: Solitary, red, infiltrated plaque measuring $9 \mathrm{~cm}$ in the major axis on the shoulder of a 47-year-old woman

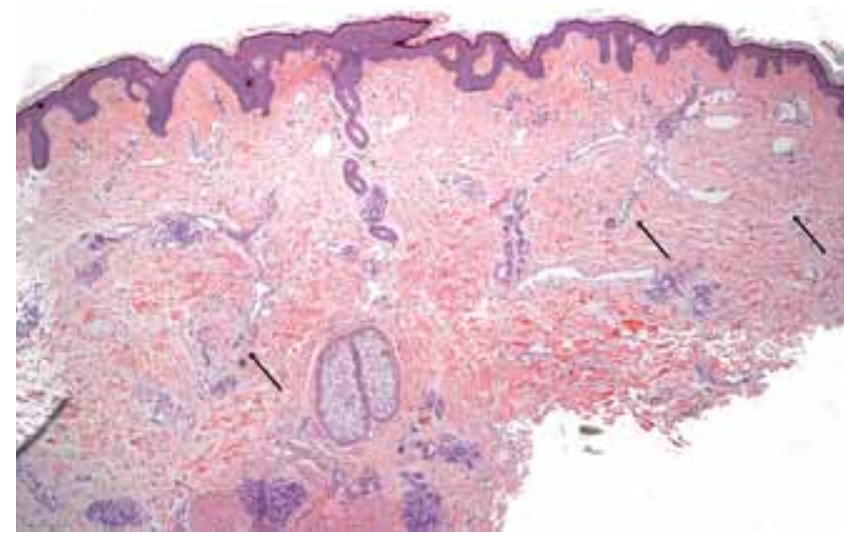

Figure 2: Vascular lobules distributed throughout the dermis in a "cannonball" pattern (arrows)

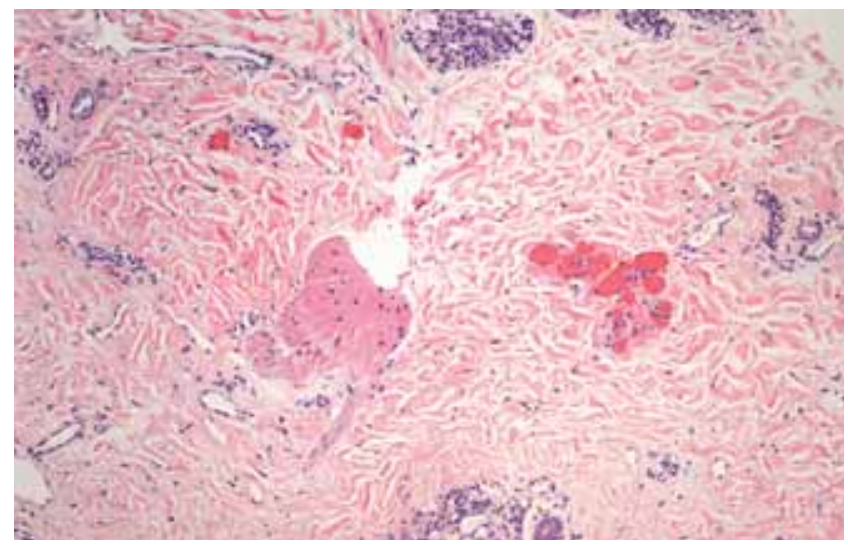

Figure 3: Vascular tufts consist of tightly packed hypertrophic endothelial cells with scanty cytoplasm and nuclei that are round, ovoid, or fusiform

\section{DISAUSSION}

TA is a benign vascular tumor, also called "Angioblastoma of Nakagawa". "The name "tufted angioma" was first proposed by Wilson Jones in $1976 .{ }^{5} \mathrm{~A}$

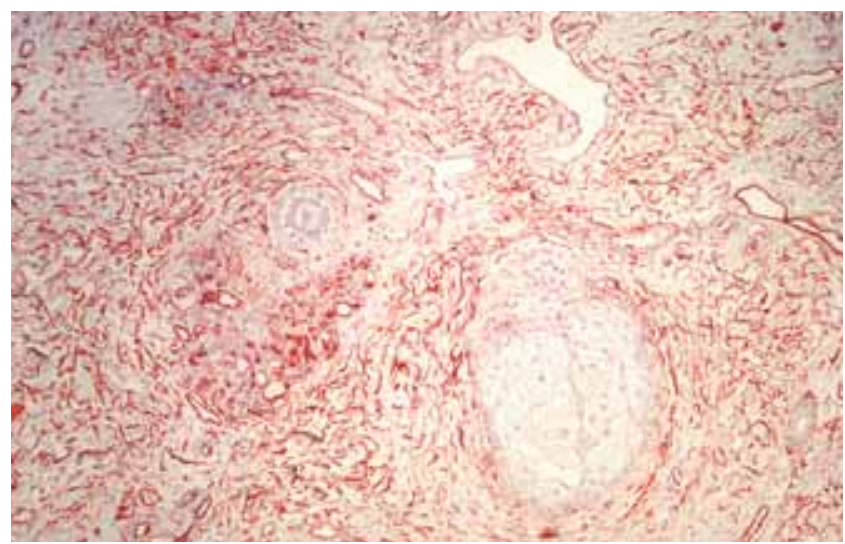

Figure 4: Immunohistochemistry showed positivity for CD31

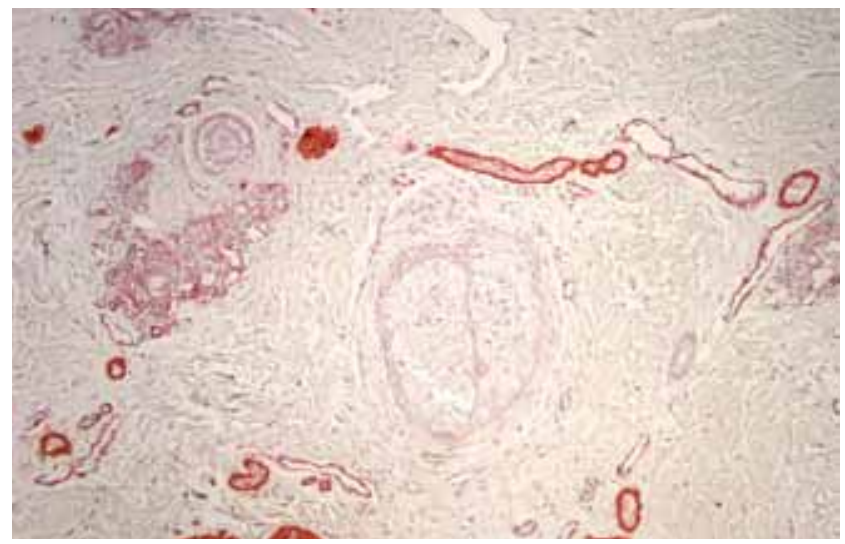

FiguRE 5: Immunohistochemistry showed negativity for smooth muscle actin

similar lesion had been previously described by MacMillan and Champion in 1971 as a progressive capillary hemangioma. ${ }^{6}$

Until now only 157 cases have been reported in the English literature. ${ }^{3}$

TAs usually affects children and young adults, but both congenital cases and late-onset cases have been also reported. Most series claim that $60-70 \%$ of TAs develop before the age of 5 years, and $25 \%$ of tumors appear before the age of 1 year. Less than $10 \%$ of TAs occur after the age of 50 years, and its onset in people older than 60-80 years is rare. ${ }^{7}$

Cases seem to appear sporadically, although a family with several members affected has been reported. ${ }^{8}$

TA is generally described as a dull red, brownred, or purple cutaneous patch or plaque with angiomatous appearance. The patch or plaque slowly enlarges for 5 months to 10 years, after which no further growth occurs. The diameter of the patches generally ranges from less than $1 \mathrm{~cm}$ to several centimeters. On pal pation, TA often has a rubbery consistency and may be painful. Some lesions may resemble connective tissue abnormalities. 
Generally, this tumor is described as solitary. However, multifocal presentations have been reported, frequently localized in the dermis and rarely involving the subcutaneous tissue.

TAs have predilection for the neck, upper chest, back and shoulder, although cases on the head and extremities have also been described. ${ }^{4}$

The lesion grows slowly and insidiously, and usually stops growing after some years with littletendency of spontaneous regression. ${ }^{4}$

The differential diagnosis includes infantile hemangiomas, congenital hemangiomas, vascular malformations and, especially in adult-onset cases, kaposiform hemangioendothelioma or Kaposi's sarcoma.

No causes of TA have yet been established. Trauma does not appear to be a predisposing factor, although a report describes the development of a lesion of tufted angioma at the site of a previous arthropod bite.

Some authors have noted the development of TA within port-wine stains, others have postulated that high hormonal levels during pregnancy and puberty may induce the devel opment of TAs. 2,9

Occasionally, TA may be associated with the platelet-trapping syndrome or Kasabach-Merritt syndrome (KMS): in this setting, the presence of petechial and ecchymotic patches should alert the physician to the development of KMS. ${ }^{10}$

\section{REFERENCES}

1. Ghosh SK, Bandyopadhyay D, Ghosh A, Biswas SK, Barma KD. Acquired multifocal TAs in an immunocompetent young adult. Indian J Dermatol. 2011;56:412-4.

2. Prieto VG, Shea CR. Selected cutaneous vascular neoplasms. A review. Dermatol Clin. 1999;17:507-20, viii.

3. Igarashi M, Oh-i T, Koga M. The relationship between angioblastoma (Nakagawa) and tufted angioma: report of four cases with angioblastoma and a literaturebased comparison of the two conditions. J Dermatol. 2000;27:537-42.

4. Jones EW, Orkin M. Tufted angioma (angioblastoma). A benign progressive angioma, not to be confused with Kaposi's sarcoma or low-grade angiosarcoma. Am Acad Dermatol. 1989;20:214-25.

5. J ones EW. Malignant vascular tumors. Clin Exp Dermatol. 1976;1:287-312.

6. Macmillan A, Champion RH. Progressive capillary haemangioma. $\mathrm{Br}$ J Dermatol. 1971;85:492-3.

7. Hebeda $C L$, Scheffer E, Starink TM. Tufted angioma of late onset. Histopathology. 1993;23:191-3.

8. Heagerty AH, Rubin A, Robinson TW. Familial tufted angioma. Clin Exp Dermatol. 1992;17:344-5.

9. Requena L, Sangueza OP. Cutaneous vascular proliferation. Part II. Hyperplasias and benign neoplasms. J Am Acad Dermatol. 1997;37:887-919.
TA s have a characteristic histol ogy consisting of a proliferation of endothelial cells forming lobules in the middle and lower part of the dermis, and in subcutaneous fat, with a specific "cannon-ball" pattern. The aggregates of endothelial cells are concentrically whorled along a preexisting vascular plexus. ${ }^{9}$ Some lobules bulge the walls of dilated thin-walled vascular structure, giving a semi-lunar appearance to the vessels: this aspect, in addition to the angiocentricity, prompted the name "Tufted Angioma". ${ }^{5}$ Immunohistochemistry demonstrates that the cells in the capillary tufts are positive for CD31, CD34 and, rarely, for smooth muscle actin. ${ }^{9}$

No specific laboratory study is useful in the diagnosis or treatment of TA. If the coexistence of Kasabach-M erritt syndrome is suspected, a complete blood cell count with a determination of the platelet count, prothrombin time and/ or activated partial thromboplastin time and full disseminated intravascular coagulation profile is indicated.

Medical treatment is not necessary for TAs, due to the benign nature and slow progression of these vascular tumors: only clinical observation is recommended. Some authors have suggested low-dose radiotherapy, surgical excision, pulse dye laser, highdose systemic steroids and subcutaneous injections of interferon- $\alpha{ }^{2} \square$

10. Enjolras $\mathrm{O}$, Wassef $\mathrm{M}$, Dosquet $\mathrm{C}$, Drouet $\mathrm{L}$, Fortier $\mathrm{G}$, J osset $\mathrm{P}$, et al. Kasabach-
Merritt syndrome on a congenital tufted angioma. Ann Dermatol Venereol. 1998;125:257-60.

M AILING ADDRESS:

Filippo Pesapane

Via Pace 9

M ilan

20145 Italy

E-mail: filippopesapane@gmail.com

How to cite this artide Pesapane F, N azzaro G, Alberti-Violetti S, Gianotti R.. A case of acquired tufted angioma in adulthood. An Bras Dermatol. 2015;90(3 Suppl 1):S16-8. 